\title{
Aneurysm, Thrombosis and Muscle Atrophy Due to Unused Arterio- Venous Fistula in A Renal Transplant Recipient
}

\author{
Dr. Vipin Chandra ${ }^{*}$, Dr. Rohit Upadhyay ${ }^{2}$, Dr. Rajesh Tiwari ${ }^{3}$
}

\author{
${ }^{1}$ Assistant Professor, Department of Urology, AIIMS, Patna - Aurangabad Rd, Phulwari Sharif, Patna, Bihar 801507, India \\ ${ }^{2}$ Associate Professor, Department of Urology, Indira Gandhi Institute of Medical Sciences (IGIMS), Allahabad bank, Bailey Rd, Sheikhpura, Patna, \\ Bihar 800014, India \\ ${ }^{3}$ Professor and Head, Department of Urology, Indira Gandhi Institute of Medical Sciences (IGIMS), Allahabad bank, Bailey Rd, Sheikhpura, Patna,
} Bihar 800014, India

DOI: $10.36347 /$ sjmcr.2020.v08i12.011

| Received: 27.11.2020 | Accepted: 23.12.2020 | Published: 24.12.2020

*Corresponding author: Dr. Vipin Chandra

Abstract

Arterio-venous fistula (AVF) is the best vascular access for hemodialysis in a patient with chronic kidney disease. Its complications during use for dialysis are well known but less has been reported about the complications of AVF that are left in situ (unused) after a successful renal transplantation. There are no specific recommendations regarding closure of AVF post renal transplantation. We are presenting a huge cephalic vein aneurysm in an unused radiocephalic fistula along with atrophy of forearm muscles in an adult renal recipient about 15 years after the creation of AVF. He was evaluated and underwent excision with uneventful recovery.

Keywords: Aneurysm, Radio-cephalic fistula, Renal transplantation.

Copyright $(\mathcal{C} 2020$ The Author(s): This is an open-access article distributed under the terms of the Creative Commons Attribution 4.0 International License (CC BY-NC 4.0) which permits unrestricted use, distribution, and reproduction in any medium for non-commercial use provided the original author and source are credited.

\section{INTRODUCTION}

Chronic kidney disease is a global health issue with a prevalence of about $10 \%$ of the world population. Kidney transplant (KT) is the best form of renal replacement therapy (RRT), but access to KT is not universal. Most patients in India receive hemodialysis (HD) as RRT in India. AVF is the best form of long term vascular access for $\mathrm{HD}$ as it has low infection rates and it provides good blood flow for HD. After a successful KT should the AVF be left in situ or not is not clear and there are no recommendations in this regard. There is fear of graft dysfunction and possible future need of HD for which AVF is left in situ mostly. While in most cases they remain asymptomatic, they can lead to complications requiring surgery and closure. Here we present a case of huge cephalic vein aneurysm in an unused radio-cephalic fistula with atrophy of fore-arm muscles in a 53 year old renal recipient about 15 years after its creation.

\section{Case Report}

A 53 year old male, presented in renal transplant OPD with a large non-pulsatile firm swelling involving almost whole left fore-arm with atrophied surrounding fore-arm muscles (Figure 1 and 2) with paraesthesia. He was diagnosed with end stage renal disease due to unknown etiology in 2001. He had undergone renal transplantation in 2003 and had good graft function (serum creatinine 1.1) at the time of presentation. A radio-cephalic arterio-venous fistula was created about two years prior to transplant surgery in 2001 as a vascular access for HD. Fistula was functional and was not ligated after successful renal transplant surgery. He had noticed gradual increase in fistula size for last 5 years, initially pulsatile but gradually became non-pulsatile. The size of the swelling continued to increase slowly. Patient was unable to use his left fore-arm because of weight of sac and on examination he had atrophied forearm muscles. He had paraesthesia in the whole fore-arm. In past history patient is known case of diabetes type2, hypertension. After the renal transplant surgery patient had been on steroids, tacrolimus and mycophenolate mofetil to prevent rejection.

On clinical examination aneurysmal sac was non-pulsatile and there was a small trophic ulcer over the sac. Ultrasound-Doppler showed large sac without any flow with thrombus. Size of the sac was around $18 \mathrm{~cm} \times 13 \mathrm{~cm} \times 8 \mathrm{~cm}$ on surface measurement.

After evaluation and taking consent, we planned for surgery under regional anesthesia, brachial block. Incision was taken near hilum of the sac (Figure3) we gradually isolated the whole sac with involved 
skin. Feeding vessel was dissected (Figure-4) and ligated before sac excision. Redundant skin was removed. Procedure completed in one hour and blood loss was about 50-60 ml. Per-operative period was uneventful. Patient recovered well with good cosmetic outcome (Figure-5) and presently on physiotherapy to gain maximum fore-arm function.

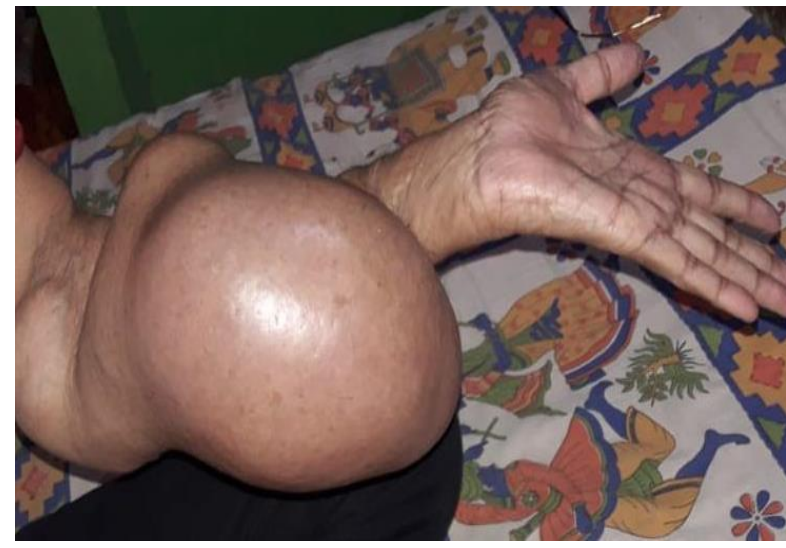

Fig-1: Pre-operative image on presentation

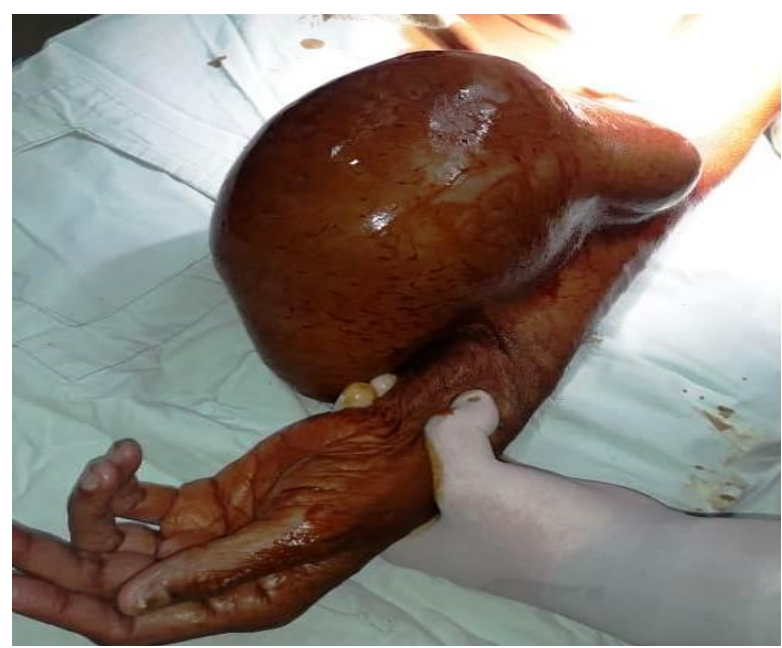

Fig-2: Image showing the huge size of the sac after draping

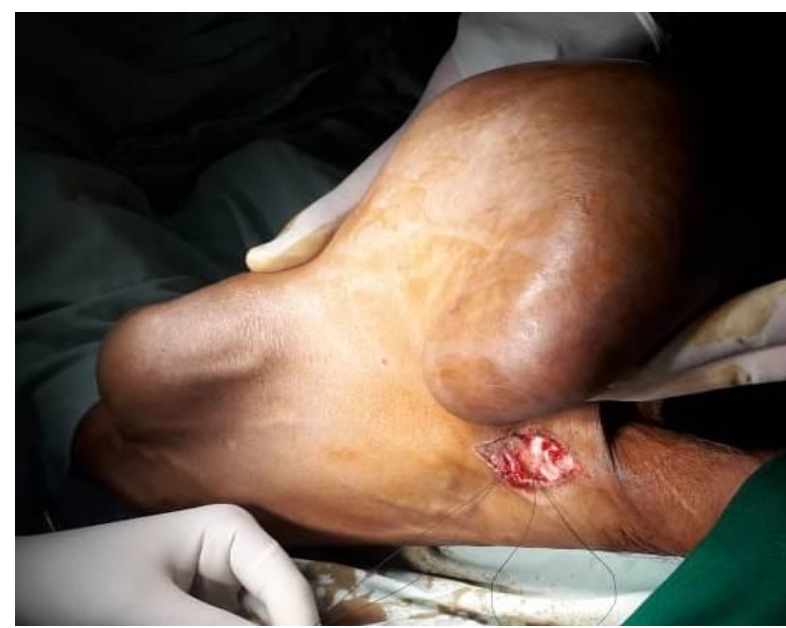

Fig-3: Image showing approach towards hilum of aneurismal sac of arterio-venous fistula

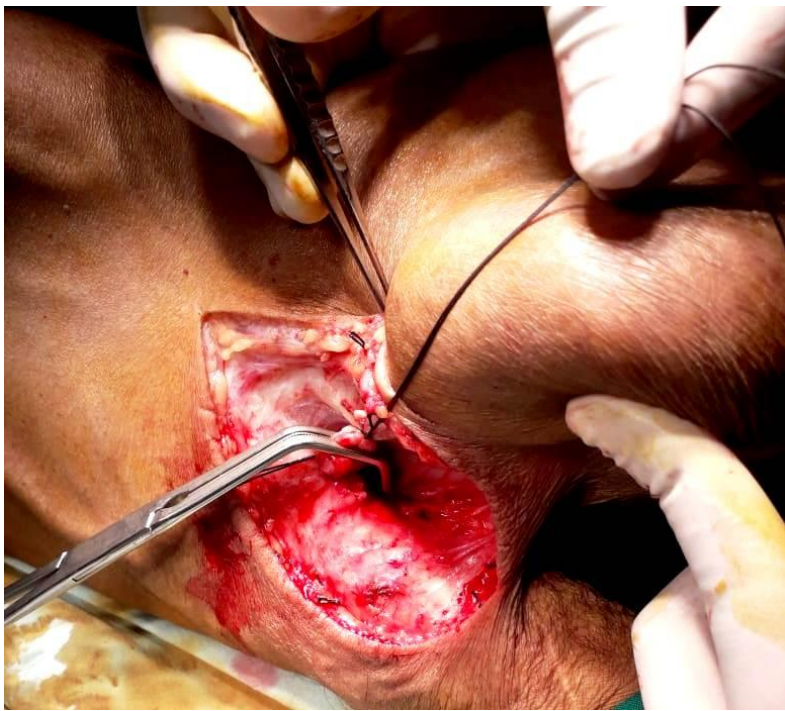

Fig-4: Ligation of the feeding vessel of the arteriovenous fistula

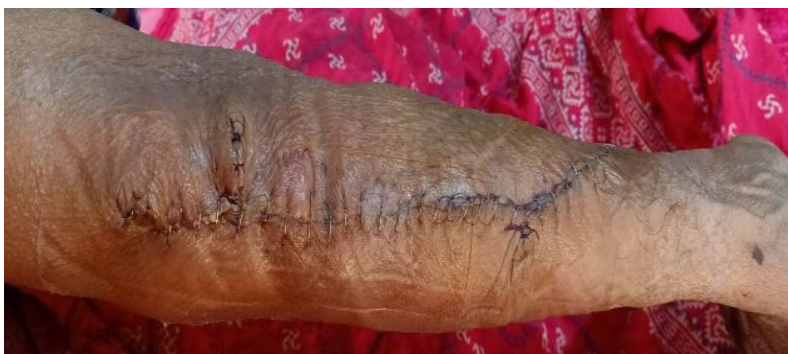

Fig-5: Image showing post operative recovery

\section{DISCUSSION}

An aneurysm is defined as a focal dilation that increases normal diameter by at least $50 \%$. The normal diameter of cephalic vein is about 2.5-2.7 mm, but after fistula creation, arterialization of vein occurs resulting in increase of luminal diameter and wall thickness. This is also called the maturation of areterio-venous (AV) fistula. This arterialization is supposed to be happen by the increase flow and pressure by the arterial blood along with release of nitric oxide (NO) by the endothelium [1]. In recent update role of reactive oxygen species (ROS) is also suggested [2]. The role of steroid and immunosuppresents were also suggested in aneurysm formation [3, 4]. There are conflicting suggestions regarding closure of AV fistula in kidney transplant recipient (KTR). Some authors suggested closure of fistula reduces cardiac load and improve graft function while others reject the benefit of fistula closure and advised to avoid unnecessary procedure [5-8]. In fact in case of graft failure that access will be useful for restarting HD. Adding to the confusion further, some recent study suggested increase chances of aneurysm development after the closure of fistula [9].

Current guidelines on postoperative care of KTRs do not give clear recommendations on management of AVF for stable kidney transplant recipients. Based on our clinical experience, the 
decision to surgically close an AVF should be individualised in every patient. Though there is a risk graft failure necessitating the need of vascular access 10 or more years from transplantation, the risk of AVFlinked complications is also significant. Furthermore, the surgical correction of those complications is not always easy to perform, as in our reported patient's case. Although many authors determine long-term graft survival using short-term graft function as a predictor, the serum creatinine level at one year is in fact closely predictive of graft survival [10]. Another parameter to consider is the fistula blood flow. Patients with a fistula blood flow $>2 \mathrm{~L} / \mathrm{min}$ are traditionally at increased risk for the development of cardiac failure and renal allograft dysfunction through high venous pressure and therefore would perhaps benefit more from fistula closure $[11,12]$.

\section{Conclusions}

We present a case of AVF complication post renal transplant. We suggest not ligating the vascular access the first year following transplantation except in cases of patients needing emergent closure such as for severe venous hypertension, risk of rupture from pseudoaneurysm, or significant high output cardiac failure or ischemic hand. Asides from these, surgical closing to prevent the onset of complications could be considered a viable option in subsets of patients who are 3 or more years from transplantation with good and stable renal function, or have a significant growth of venous aneurysms, have a high AVF flow rate or are young in age.

\section{Conflict of Interest: None.}

\section{REFERENCES}

1. Eugster T, Wigger P, Bo“lter S, Bock A, Hodel K, Stierli P. Brachial artery dilatation after arteriovenous fistulae in patients after renal transplantation. A 10-year follow-up ultrasound scan. J Vasc Surg. 2003; 37:564-7.

2. Castier Y, Lehoux S, Hu Y, Foteinos G, Tedgui A, $\mathrm{Xu}$ Q. Characterization of neointima lesions associated with arteriovenous fistulas in a mouse model. Kidney Int. 2006; 70:315-20.

3. Santangelo ML, Bracale UM, Carlomagno N, De Rosa D, Spiezia S, Scotti A, Tammaro V, Porcellini M, Renda A. Kidney transplantation and large anastomotic pseudoaneurysm. Ann. Ital. Chir. 2013;84:275-9.
4. Sirico ML, Guida B, Procino A, Pota A, Sodo M, Grandaliano G, Simone S, Pertosa G, Riccio E, Memoli B. Human mature adipocytes express albumin and this expression is not regulated by inflammation. Mediators of Inflammation. 2012 Jan 1;2012.

5. Zheng H, Bu S, Song Y, Wang M, Wu J, Chen J. To Ligate or Not to Ligate: A Meta-analysis of Cardiac Effects and Allograft Function following Arteriovenous Fistula Closure in Renal Transplant Recipients. Annals of Vascular Surgery. 2020 Feb 1;63:287-92.

6. Rao NN, Stokes MB, Rajwani A, Ullah S, Williams K, King D, Macaulay E, Russell CH, Olakkengil S, Carroll RP, Faull RJ. Effects of arteriovenous fistula ligation on cardiac structure and function in kidney transplant recipients. Circulation. 2019 Jun 18;139(25):2809-18.

7. Yaffe HC, Greenstein SM. Should functioning AV fistulas be ligated after renal transplantation?. The journal of vascular access. 2012 Oct;13(4):405-8.

8. Weekers L, Vanderweckene P, Pottel H, Castanares-Zapatero D, Bonvoisin C, Hamoir E, Maweja S, Krzesinski JM, Delanaye P, Jouret F. The closure of arteriovenous fistula in kidney transplant recipients is associated with an acceleration of kidney function decline. Nephrology Dialysis Transplantation. 2016 Oct 17:gfw351.

9. Dinoto E, Bracale UM, Vitale G, Cacciatore M, Pecoraro F, Cassaro L, Monte AI, Bajardi G. Late, giant brachial artery aneurysm following hemodialysis fistula ligation in a renal transplant patient: case report and literature review. General thoracic and cardiovascular surgery. 2012 Nov 1;60(11):768-70.

10. Hariharan S, Mcbride MA, Cherikh WS, Tolleris CB, Bresnahan BA, Johnson CP. Post-transplant renal function in the first year predicts long-term kidney transplant survival. Kidney international. 2002 Jul 1;62(1):311-8.

11. MacRae JM, Pandeya S, Humen DP, Krivitski N, Lindsay RM. Arteriovenous fistula-associated high-output cardiac failure: a review of mechanisms. American Journal of Kidney Diseases. 2004 May 1;43(5):e21-1.

12. Van Duijnhoven EC, Cheriex EC, Tordoir JH, Kooman JP, van Hooff JP. Effect of closure of the arteriovenous fistula on left ventricular dimensions in renal transplant patients. Nephrology Dialysis Transplantation. 2001 Feb 1;16(2):368-72. 